\title{
Study on Ecological Economic Zone Division in the County Based on Comprehensive Evaluation of Ecological Carrying Capacity
}

\author{
Zhu Tianming \\ School of Urban Resource and Environment \\ Yancheng Teachers University, Yancheng 224000, China \\ ztm1981@sohu.com
}

\author{
Zhang Luocheng \\ Nanjing Institute of Geography and Limnology, \\ CAS, Nanjing 210008, China \\ Lchzhang@niglas.ac.cn
}

\begin{abstract}
Based on the related study of resource carrying capacity, environmental carrying capacity and ecological carrying capacity, the paper proposes the concept of comprehensive carrying capacity in the basis of "nature-ecologyeconomy" compound system, and constructs the corresponding evaluation index system and models. Taking Jintan city as an example, the paper evaluates the difference of the comprehensive ecological carrying capacity of Jintan, and then proposes ecological-economic zone scheme. The paper divides Jintan into four types of ecological and economic area: Ecological protection and tourism development area, Water-towns protection and tourism development area, Modern city and industrial development area, Traditional industries integration and development area. According to the development area, different ecological and economic development strategies should be taken.
\end{abstract}

Index Terms-comprehensive ecological carrying capacity, evaluation, eco-economic division, Jintan city

In recent years, China has achieved rapid economic development, but also paid the heavy costs of resources and environment. Extensive mode of economic growth leads to resources consumption and environmental degradation. The imbalance between supply and demand of resources and ecological overload phenomena has already appeared in some areas. The goal of carrying capacity study is to regulate human activities and promote the sustainable development of regional economic society, based on the scientific assessment of regional eco-environment influencing human activities. The study of carrying capacity begins in 1960s, and it has always been the study focus of geography, ecology, resources science and environmental science, etc. for half a century. The research mainly involves the connotations of resources carrying capacity, environmental carrying capacity, and ecological carrying capacity, and also the evaluation models and methods ${ }^{[1-5]}$, and related researches are mainly concentrated in the carrying capacity of single elements rather than comprehensive carrying capacity. With the growing development of industrialization and urbanization in China, ecological environment in some areas has been to a large extent converted. In these areas, resource, environment, ecology and society have shown a deep coupling state, and thus form characteristics of "nature-ecology-economy" compound system. Therefore, based on the reality of some economically developed regions, using existing research of resources carrying capacity, environmental carrying capacity and ecological carrying capacity for reference, the paper carries out the evaluation research on "nature-ecology-economy" compound system can make more valuable guide to economic activities and human society, and builds a higher level of ecological civilization.

\section{GENERAL SITUATION OF THE RESEARCH AREA}

Jintan city is located in Yangtze River delta economic area, that is, North latitude $31^{\circ} 33^{\prime} 42^{\prime \prime} \sim 31^{\circ} 53^{\prime} 22^{\prime \prime}$, East longitude $119^{\circ} 17^{\prime} 45^{\prime \prime} \sim 119^{\circ} 44^{\prime} 59^{\prime \prime}$. Jintan city has an area of 975.46 square kilometers including land area of 781.27 square kilometers, water area of 194.22 square kilometers, and builtup area of 22.8 square kilometers. During recent years, Jintan was developing fast in the aspects of economy and society. Its average annual growth is $15.6 \%$, with per capita GDP as 56,000 yuan. Relying on superior location and resource advantages, Jintan city gradually forms the industrial structure of photovoltaic, machinery and electronics, textile and clothing, salt chemical industry etc.. At the same time, the growing development of the structure brings obvious pressure of resources and environment. Therefore, Jintan city is a typical area of ecological and environmental problems caused by the interaction of "nature-ecology-economy" composite system in Yangtze River delta.

\section{EVALUATION MODEL AND DATA SOURCES}

\section{A. Concept of comprehensive ecological carrying capacity and evaluation model}

Based on urban ecosystem theory, considering the comprehensiveness, time-space relativity, and modulatory character, it can define comprehensive carrying capacity, based on "nature-ecology-economy" compound system, as the following: in a specific period and objective, an area's carrying capacity of resource endowment, ecological environment, infrastructure and public services on the regional population and economic and social activities. Comprehensive ecological carrying capacity includes not only the foundation carrying capacity, such as soil, water resources, and environment capacity provided by ecological environment system, but also the quantity of the soil, water resources, environment capacity claimed by territorial anthropo-system from the ecological environment system and its influencing factors; and also the direct constraints influenced by the industrial structure, distribution, quality of life requirements and level of infrastructure etc.. Therefore, the supply capacity of human system determines the threshold of carrying capacity, while requirement and technological level of human system determines the present value of carrying capacity.

Foundation: under the auspices of National Natural Sciences Foundation of China (No. 40601098, No. 40801222) and Jiangsu province education department natural science research item (10KJD170004).

Corresponding author: Zhang Luocheng. Email: lchzhang@niglas.ac.cn 
Based on the "State-pressure-response" analysis of unban ecological system, the "nature-ecology-economy" comprehensive carrying capacity can be divided into resources and environment carrying capability, economic and social pressure, and government regulation capacity in order to understand well and do quantitative evaluations ${ }^{[6]}$.

According to the successful experiences of evaluation method of comprehensive carrying capacity applied in Seoul in South Korea, Taibei, Beijing and Cixi etc., comprehensive carrying capacity is influenced by regional resource and environment basement, population and economic development pressures, and unban management and regulation. Whether the quality of regional resources and environment basement is good or bad determines the size of original capacity of the basement. Population and economic development pressure influences comprehensive carrying capacity. As the pressure increases, the carrying capacity decreases in the form of reciprocal index. When the pressure reaches a maximum value (100), carrying capacity decreased about $30 \%$, that is, about $70 \%$ of the carrying capacity will not be weakened because of increased pressure. When the pressure is zero, regional carrying capacity is the original resources and environment carrying capacity (Figure 1). Government management and regulation affect the follow-up bearing capacity. The stronger the regulation capacity, the higher the follow-up carrying capacity is. However, when it reaches a certain level, follow-up carrying capacity will maintain at a particular level without playing obvious function (Figure 2).

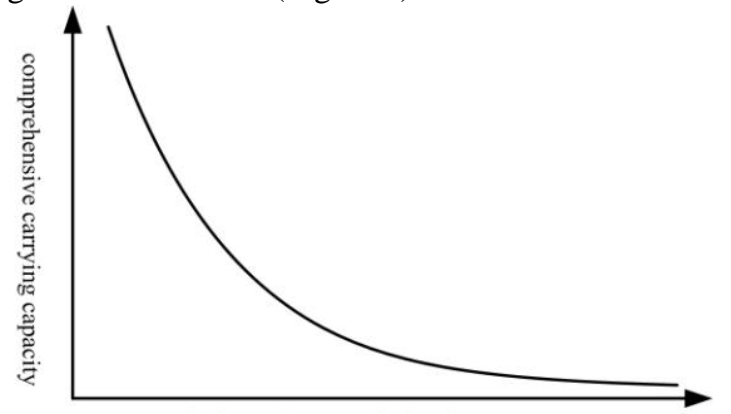

population and economic development pressure

Figure 2 Relation graph between comprehensive carrying capacity and population and economic development pressure

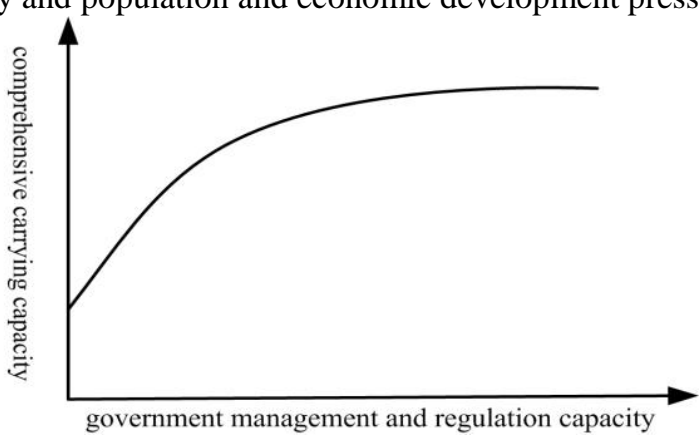

Figure 3 Relation graph between comprehensive carrying capacity and government management and regulation capacity

The comprehensive carrying capacity in the area consists of amended resources and environment carrying capacity and follow-up carrying capacity obtained by regulation. It can be measured by comprehensive carrying coefficient $F$. The formula is as follows:

$$
F=A * e^{\left(-0.3^{*} P\right)}+\ln (S+1)
$$

Note: A stands for resource and environment carrying capacity, P for population and economic development pressure, $\mathrm{S}$ for government management and regulation capacity

\section{B. Construction of index system and evaluation method.}

According to the connotation of comprehensive carrying capacity and evaluation model, comprehensive ecological carrying capacity is got by regional resources and environment carrying capacity, population and economic development pressure and government management and regulation capacity through the results of model calculations. The regional resource and environment carrying capacity, population and economic development pressure and government management and regulation capacity are evaluated through the method of the index system.

According to the construction of index systems, and data procurability, evaluation index system of constructing resource and environment carrying capacity, population and economic development pressure, and government management and regulation capacity in Jintan city can be seen in Table 1 . The evaluation method of index system concerns integrating index information of different units and determining the index weight. The processing method of different dimensions in this paper is carried out through target standardization methods, and the calculation process adopts the method of extreme standardization. Index weight reflects the importance and influencing degree of each index's evaluation targets. The determination of index weight is fully based on inherent characteristics carrying status of regional resources and environmental factors, regional characteristics of the economic and social pressures, and the actual situation of government regulation capacity. In order to determine more objective and reasonable index weight, and reduce the impact of experts' subjective will, the paper adopts analytic hierarchy process, combined the method of the expertise judgment to determine the weight of each index, see (table 1).

Table 1 evaluation index system and index weight of comprehensive carrying capacity in Jintan

\begin{tabular}{|c|c|c|c|}
\hline $\begin{array}{l}\text { first } \\
\text { grade } \\
\text { index } \\
\text { es }\end{array}$ & $\begin{array}{c}\text { Second } \\
\text { grade } \\
\text { indexes and } \\
\text { index } \\
\text { weight }\end{array}$ & $\begin{array}{c}\text { Second grade } \\
\text { indexes and index } \\
\text { weight }\end{array}$ & Calculation Method \\
\hline \multirow{7}{*}{ 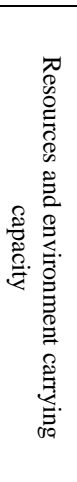 } & \multirow{4}{*}{$\begin{array}{l}\text { Quality of } \\
\text { Water } \\
\text { environment } \\
(0.32)\end{array}$} & $\begin{array}{l}\text { chemical oxygen } \\
\text { demand }(0.25)\end{array}$ & \multirow{4}{*}{$\begin{array}{l}\text { Average data from water } \\
\text { quality monitoring point, is } \\
\text { calculated by inverse distance } \\
\text { weighted interpolation of } \\
\text { ArcGIS's spatial analysis } \\
\text { method }(\mathrm{mg} / \mathrm{l}) \text {. }\end{array}$} \\
\hline & & $\begin{array}{c}\text { ammonia nitrogen } \\
(0.25)\end{array}$ & \\
\hline & & $\begin{array}{c}\text { volatile phenol } \\
(0.25)\end{array}$ & \\
\hline & & petroleum $(0.25)$ & \\
\hline & \multirow{3}{*}{$\begin{array}{c}\text { Quality of } \\
\text { atmospheric } \\
\text { environment } \\
(0.24)\end{array}$} & $\begin{array}{c}\text { sulfur dioxide } \\
(0.33)\end{array}$ & \multirow{2}{*}{$\begin{array}{l}\text { Data from air quality } \\
\text { monitoring point, is } \\
\text { calculated by inverse distance } \\
\text { weighted interpolation of } \\
\text { ArcGIS's spatial analysis } \\
\text { method }(\mathrm{mg} / \mathrm{m} 3) \text {. }\end{array}$} \\
\hline & & $\begin{array}{l}\text { nitrogen oxides } \\
\quad(0.33)\end{array}$ & \\
\hline & & $\begin{array}{l}\text { influence radius of } \\
\text { harmful gas } \\
(0.33)\end{array}$ & $\begin{array}{l}\text { Do buffer analysis of } \\
\text { chemical enterprises with } \\
\text { scales, evaluate influences of } \\
\text { the harmful gas }(\mathrm{km}) \text {. }\end{array}$ \\
\hline
\end{tabular}




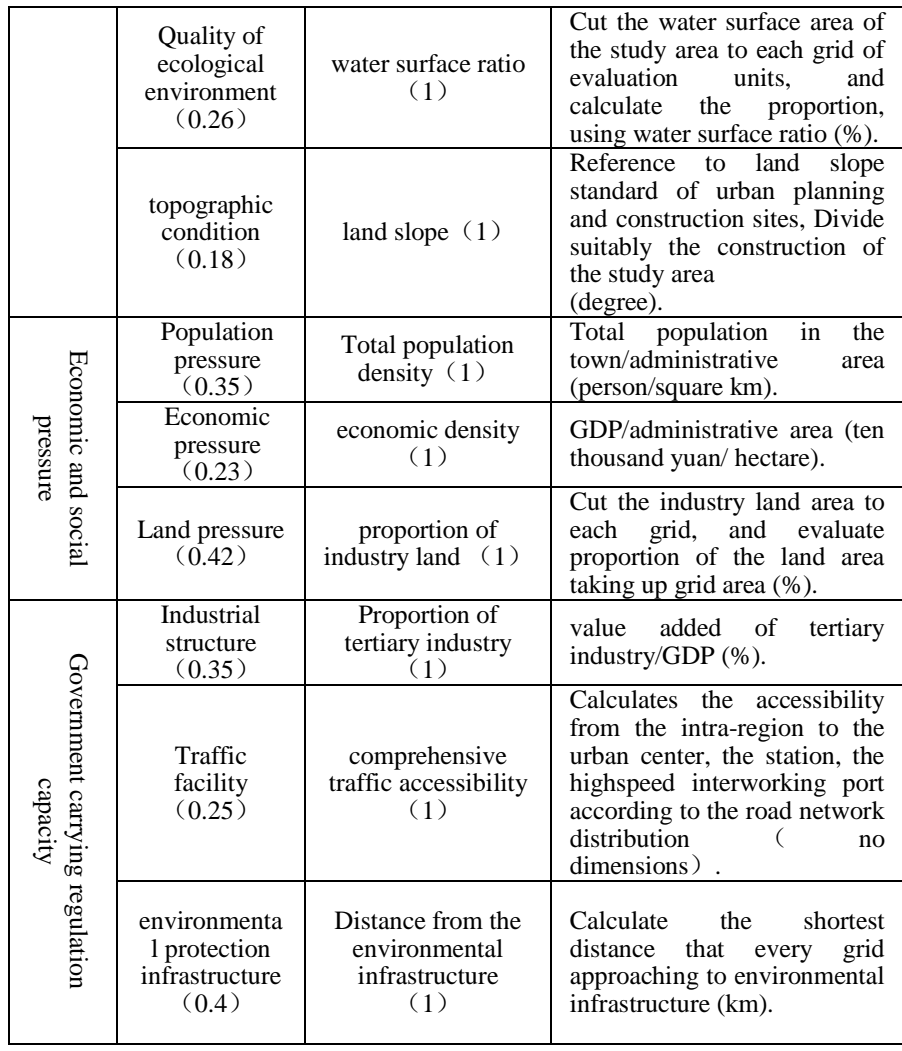

\section{Data resources and instructions of processing methods}

The original data in this paper mainly come from Jintan Environmental Protection Agency, Land Bureau, Bureau of Statistics and other government departments, taking some data in the government official website as the supplement. Spatial data are mainly based on Changzhou basic geographic information data. Evaluation Unit is mainly based on the characteristics of elements, respectively taking the equalization of the grid unit and administrative unit as a single element of space evaluation unit. For example, the evaluation unit of population and economic statistical data is street, town and district, and the evaluation unit of water environment quality and atmospheric environment quality is $500 \mathrm{~m} \times 500 \mathrm{~m}$ grid. The grid is taken as the integrated evaluation unit and classification unit. Administrative unit data generate the grid unit value through segmentation or interpolation. Data analysis and processing is mainly based on ARCGIS9.3 and SPSS16.0 software

\section{ANALYSIS OF EVALUATION RESULTS}

\section{A. The evaluation result of resources and environment carrying capacity}

The index value of the four types of elements representing the water quality of the environment, the quality of atmospheric environment, environmental quality, and topographic conditions is standardized and weighted sum, and then standardized once again, ensure that the superposition of the scores in the grid are still between 0 and 100. The higher score indicates that the resources and environment carrying capacity is higher. And the evaluation result shows that the resources and environment carrying capacity is higher in southeastern region and low in northwestern region of Jintan.

\section{B. Evaluation results of economic and social pressure}

The index value of the three types of elements representing the population pressure, economic pressure, and land pressure is standardized and weighted sum, and then standardized once again, ensure that the superposition of the scores in the grid are still between 0 and 100. The higher score indicates that the economic and social pressure is bigger. And the evaluation result shows that economic and social pressure is the greatest in Jincheng town, medium in Zhixi town ,Zhulin town, Zhiqian town, Yaotang town and Rulin town, and small in Xuebu town.

\section{Evaluation results of government carrying regulation capacity}

The index value of the three types of elements representing the industrial structure, transport facilities and environmental protection infrastructure is standardized and weighted sum, and then standardized once again, ensure that the superposition of the scores in the grid are still between 0 and 100. The higher score indicates that the the government carrying regulation capacity is powerful. And the evaluation result shows that the government carrying regulation capacity is powerful in northwestern area and weak in southern and western area.

\section{Evaluation results of comprehensive ecological carrying capacity}

According to the comprehensive carrying capacity model, the evaluation results of comprehensive carrying capacity has been gotten, and furthermore, divided into high carrying capacity area, medium carrying capacity area and low carrying capacity area by the natural breakpoint methods. The scores of the high carrying capacity area is between $0.94-1.48$, covering an area of 221 square kilometers, locating in southern region of Jintan and in some areas of east coast of Changdang Lake and taking up $22.6 \%$ of Jintan area. The scores of the medium carrying capacity area are between $0.75-0.94$, covering an area of 543 square kilometers, locating in vast areas of north and west of Jintan and taking up 55.8\% of Jintan town. The scores of the low carrying capacity area are between $0.35-0.75$, covering an area of 211 square kilometers, locating in the town of Runlin, Zhulin, and the northwest and western regions of Jintan and taking up $21.6 \%$ of Jintan town. According to the major restriction factors, the low carrying capacity area can be further divided into two types: natural low carrying capacity area and the reinforcing regulation area. The natural low carrying capacity area is located in mountain regions of Maodong in the west of Jintan. The major restriction factors are those unchangeable natural conditions (such as: topographies). The reinforcing regulation area, where the main restricting factors are controllable, such as the water environment and the government regulation etc., is located in the town of Rulin,Zhulin and the northwest region of Zhixi.

\section{JINTAN ECOLOGICAL AND ECONOMIC ZONE SCHEME}

Ecological and economic zone is a new model of managing the sustained development of regional society and economy 
from the macro perspective. The purpose is to coordinate the relation between regional economic development and ecological environment protection and rational use of natural resources. The paper puts forward to the Jintan ecological and economic zone scheme, from the zone result of the evaluation of Jintan comprehensive carrying capacity, combined with its socio-economic development and the status of spatial distribution(Figure 3).

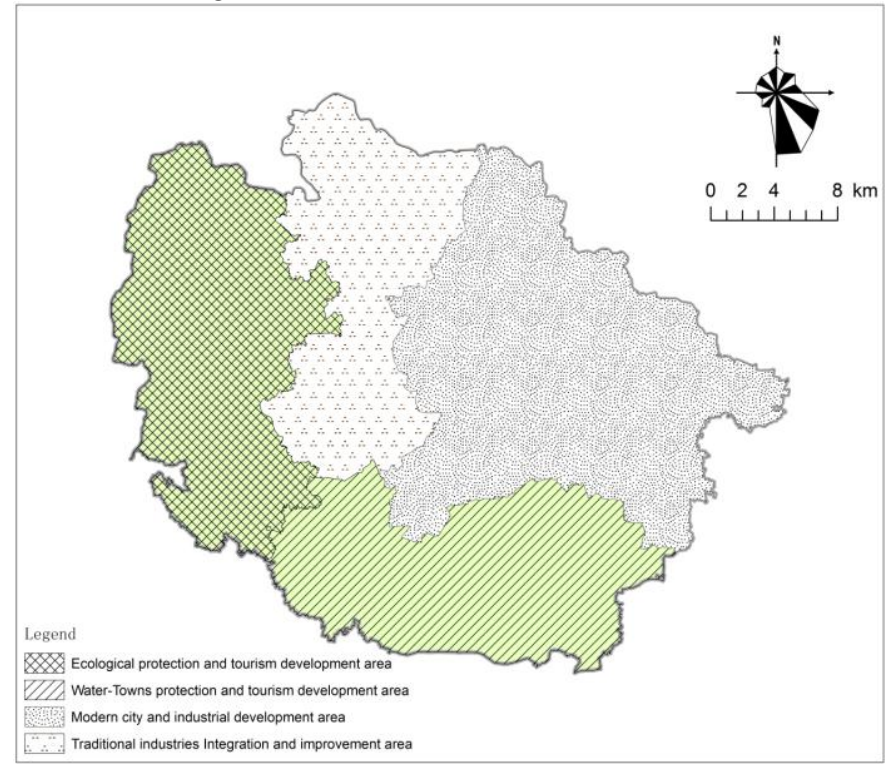

Figure 3 Ecological economic zone scheme in Jintan

Modern city and industrial development area is the center of politics, economy, business, finance, culture, technology. Its development is mainly formed through the integrated development of Jincheng town and Yaotang town, and it has great impact on other functional areas. The development of secondary industry mainly focuses on developing modern manufacturing, relying on the Jintan economic and technical development zone, Jincheng industrial zone, and Jingdong industrial park zone. The tertiary industry mainly focuses on developing modern business, transportation, real estate, technical services, and information services, relying on the development of Jintan old town and the upcoming construction of Binhu new town.

Traditional industries integration and development area is the future manufacturing basement in Jintan. Taking advantage of approaching Jintan downtown, and Yangli highwayand Yanjiang highway, it can integrate the original development of Zhixi town, Zhulin town, Zhiqian town, promote the integration and development of traditional industries. The secondary industry mainly focuses on developing high-tech industries, supplemented by labor-intensive industries, integrating management and research\& design industries. It emphasizes on the development of textile clothing industry, fine chemical industry, new materials industry, and machinery and electronics industry, etc., integrating Jingxi industrial park and industry concentrating area to form industrial development cluster.

Ecological protection and tourism development area relies on the town of Xuebu. The development targets of this area are experiencing Taoist culture and building the leisure and health preservation resort. The function orientation of ecological economy is the ecological protection and tourism development. The tourism development focuses on the Taoist Culture and Maoshan natural scenery. Through improving ecological agriculture, catering, hotel services and other related supporting industries, this area becomes an important tourism and leisure resort in the Yangtze River Delta.

Water-towns protection and tourism development area relies on the town of Rulin and Zhiqian. Future development is primarily intended for residents of Metropolitan recreation needs, constructs metropolitan tourism and leisure bases with the characteristic of waterside landscape features and cultural experience.

\section{CONCLUSIONS}

Comprehensive evaluation results show that, there are large differences among comprehensive ecological carrying capacity in Jintan. Based on the evaluation of comprehensive carrying capacity, the paper puts forward to the Jintan ecological and economic zone scheme. The whole Jintan city is divided into four types of ecological economic area, that is, maoshan ecological protection and tourism development area; integration and development of traditional industries in central area; modern city and industrial development area in eastern part; rivers and lakes culture and tourism development area in southern part. The interaction mechanism of "nature-ecologyeconomic" composite system is extremely complex, furthermore, there are many uncertain factors in choosing indexes in the process of evaluation. The paper summarizes the relations among resources and environment carrying capacities, economic and social pressure, and government carrying regulation capacity only using the method of simplified models, which leads to some deficiencies. These deficiencies need systematical study and further development of index system.

\section{REFERENCES}

[1] Yan X P, Zhang Z L. The system dynamics study on the population carrying capacity of land in Qinghai province. Geography Science, No. 1. pp.69-77, 1993

[2] Guo X R, Mao X Q, Rang Z H. Research progress in environmental carrying capacity in China. China population, resources and environmental. No. 3. pp.28-30, 2000

[3] Meng Q X, Chang Q R, Zhang J H. Discussion on land bearing capacity and improving methods in agriculture and pasturage interlaced zone of northern Shaanxi. Agricultural Research in the Arid Areas, No. 1 pp.8-10, 2003

[4] Cheng G D. Evolution of the Concept of Carrying Capacity and the Analysis Framework of Water Resources Carrying Capacity in Northwest of China. Journal of Glaciolgy and Geocryology. No. 4. pp.361-366, 2002

[5] Yao Z J, Wang J H, Jiang D. Advances in study on regional water resources carrying capacity and research on its theory. Advances In Water Science. No. 1. pp.113-114, 2002

[6] Wang D, Cheng S. Study on the Method of Zoning by Urban Carrying Capacity. Progress in geography. NO.5. pp.577-584, 2011 